\title{
Prevalence and risk factors of pre hypertension and hypertension among postmenopausal women of urban slums of Hyderabad
}

\author{
Sudha Bala ${ }^{1, *}$, A. Praveena ${ }^{2}$, D. Meena ${ }^{3}$ \\ ${ }^{1}$ Assistant Professor, ${ }^{2,3}$ Tutor, Dept. of Community Medicine, ESIC Medical College, Hyderabad, Telangana, India
}

*Corresponding Author:

Email: dr.sudhabala78@gmail.com

\begin{abstract}
Introduction: Hypertension is the leading risk factor as well as component of cardiovascular diseases which is on rise and emerging as a major public health problem. Due to the paucity of studies among postmenopausal women on pre hypertension and hypertension this study was taken up in urban slums of Hyderabad.

Aim and Objectives: 1 . To determine the prevalence of pre hypertension and hypertension among post menopausal women and; 2. To assess their relationship with risk factors.

Materials and Methods: A community based cross sectional study was undertaken in urban slums of Hyderabad among four hundred and thirty post menopausal women. Detailed history on dietary, lifestyle, personal habits, reproductive and socio demographic variables was taken to relate with pre hypertension and hypertension which was graded using Joint national committee (JNC 7).

Results: The prevalence of pre hypertension was $29 \%$ and hypertension was $35 \%$ among post menopausal women. Significant association was found with increasing age, duration of menopause, family history of hypertension, extra salt intake and sedentary lifestyle.

Conclusions: Hypertension among post menopausal women poses a major threat due to complications associated with it and these are much amenable by primordial and primary preventive strategies.
\end{abstract}

Keywords: Pre hypertension, Hypertension, Modifiable risk factors, JNC7, Primordial prevention, Post menopause.

\section{Introduction}

Menopause is a physiological event but with a potential for precipitating chronic disorders in vulnerable women- "Marker for diseases". Hypertension is one among the cardiovascular disease and also the third most risk factor in South asia. ${ }^{1}$ Indians are also experiencing increased prevalence of cardiovascular diseases due to the epidemiological transition where by there are changes in lifestyle, eating habits, tobacco and alcohol usage and inadequate physical activity. Women after attaining menopause have higher chances of hypertension due to the increased plasma renin angiotensin activity. ${ }^{2}$ Hypertension is becoming a public health challenge especially among women as they have increased life expectancy when compared to men. As a consequence of this women are spending more than one third of their life during this post menopause period. ${ }^{3}$

According to Barker's theory- chronic diseases have their origin in utero and the clinical presentation would depend on genetic, environmental, social and cultural factors. ${ }^{4}$ Among these identification of modifiable risk factors are amenable for primordial and primary prevention. Thereby it is very essential to screen post menopausal women for determining Pre hypertension and hypertension to prevent complications and also adopt strategies to intervene at early stage by lifestyle modifications. This study has made an attempt with an aim and objectives- to determine the prevalence of pre-hypertension and hypertension among post menopausal women and also to assess their relationship with risk factors.

\section{Materials and Methods}

This study was community based cross sectional study conducted at 5 urban slums of south west Hyderabad having a total population of 13,023 with estimated women $>40$ years as 986 . By adopting simple random sampling and using lottery method post menopausal women fulfilling the criteria were chosen.

Based on various studies in India among urbanized areas an average of $50 \%$ of prevalence was taken to calculate the sample size using the formulae $4 \mathrm{pq} / \mathrm{l}^{2}$ $(4 \times 50 \times 50 / 25=400)$ and non response rate $10 \%$ about four hundred and thirty participants were studied.$^{5-7} 534$ women were contacted and those women who fulfilled the criteria of natural menopause above the age group of 40 years, not sick and who gave consent were included in the study. Premature and surgical menopause women were excluded from the study. On an average 30-35 were selected from each slum for feasibility. A pretested questionnaire schedule was used to elicit information on socio demographic variables; reproductive parameters; history of oral contraceptive usage, family history of hypertension; dietary history consisting of information on type of diet, Intake of fruits/ vegetables; extra salt intake in the form of papads, processed junk food, chutneys, pickles; extra fat intake using food frequency questionnaire. Any intake greater than three times a week was considered as regular intake. Personal history included consumption of alcohol and tobacco users. Lifestyle was classified as sedentary, moderate and heavy. Height was measured without slippers to the nearest 0.1 $\mathrm{cm}$ and weight was measured using digital weighing 
machine to nearest $0.1 \mathrm{~kg}$. Body mass index was calculated as per grading of obesity for Asians as $<18.5$ -underweight, $18.5-23$ as normal, 23.1-27.5 as overweight and $>27.5$ as obese. ${ }^{8}$

Blood pressure for all the participants was measured by the auscultatory method in sitting position using a mercury sphygmomanometer in left arm twice, 5 minutes apart and an average of two readings was taken. The team had been trained in the standardized technique of blood pressure measurement by skilled medical practitioner. In case where the two readings differed by over $10 \mathrm{~mm}$ of $\mathrm{Hg}$, a third reading was obtained and the three measurements were averaged. Normal blood pressure was taken as less than 120 mmHg-systolic and less than $80 \mathrm{mmHg}$-diastolic. As per US seventh joint national committee on detection, evaluation and treatment of hypertension (JNC VII) criteria - participants with the blood pressure values of 120 to $139 \mathrm{mmHg}$ (systolic) or 80 to $89 \mathrm{mmHg}$ (diastolic) were classified under pre-hypertension category. Stage-I hypertension was taken as 140 to 159 mmHg-systolic or 90 to $99 \mathrm{mmHg}$-diastolic, whereas Stage- II hypertension was taken as blood pressure of more than $160 \mathrm{mmHg}$-systolic or more than 100 mmHg-diastolic. ${ }^{9}$

Institutional ethical committee approval was obtained and written consent was taken from the participants. Data was entered and analysed using Microsoft excel 2010; Frequency, mean and standard deviations were calculated. Tests of significance was calculated using Chi- square wherever required to depict association with the risk factors.

\section{Results}

Socio Demographic Characteristics of Participants: Majority of the postmenopausal women 193 (44.8\%) belonged to the age group of 51-60 years. Most of them were illiterates $286(67 \%)$. As per occupation majority were housewives $319 \quad(74.3 \%)$. Based on socioeconomic status as per modified BG Prasad's classification majority belonged to lower middle class $133(30.9 \%){ }^{10}$

Prevalence of Hypertension among Postmenopausal Women: In urban postmenopausal women the prevalence of Pre HTN was 123(29\%), HTN-I was $70(16 \%)$ and HTN-II was $81(19 \%)$ [including already known hypertensive]. (Fig. 1)

Mean systolic blood pressure was $134.27+21.16 \mathrm{~mm}$ of hg and mean diastolic blood pressure was $88.32 \pm 14.72$ $\mathrm{mm}$ of hg.

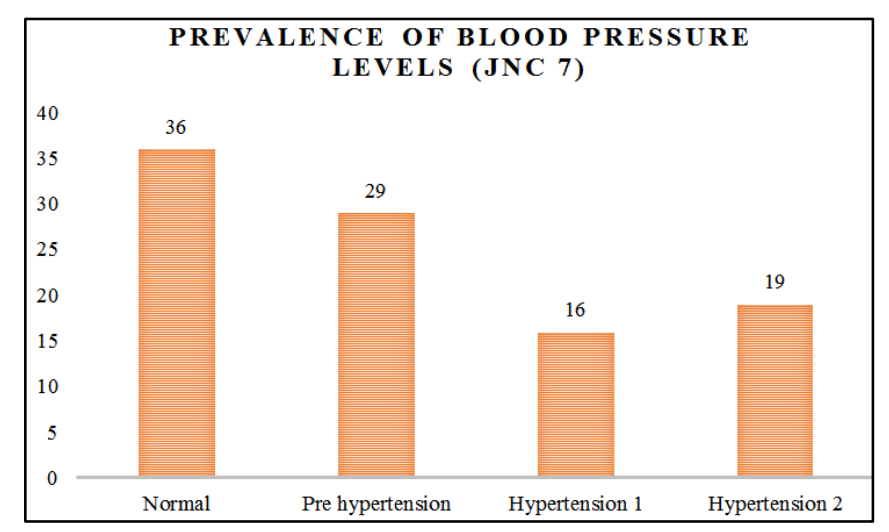

Fig. 1: Prevalence of blood pressure levels (JNC 7)

Various risk factors were determined classified as Non modifiable and Modifiable. Average number of live children were three. Duration of menopause was less than 5 years among 108(25.1\%), 5-10 years of duration among $113(26.3 \%)$ and greater than 10 years among 209(48.6\%). Mean duration since menopause was $12 \pm 7.45$ years. Statistically significant association was found with increasing age, duration of menopause and family history of hypertension among non modifiable risk factors. Table 1. No significant association was found with parity in our participants.

Table 1: Non modifiable risk factors associated with pre hypertension and hypertension

\begin{tabular}{|l|c|c|c|c|c|c|}
\hline $\begin{array}{c}\text { Non modifiable Risk } \\
\text { factor }\end{array}$ & $\begin{array}{c}\text { Normal } \\
\text { N=156 }\end{array}$ & $\begin{array}{c}\text { Prehypertension } \\
\mathbf{N = 1 2 3}\end{array}$ & $\begin{array}{c}\text { Hypertension } \\
\mathbf{N = 1 5 1}\end{array}$ & Total N=430 & $\begin{array}{c}\text { Chi square } \\
\text { Df }\end{array}$ & P value \\
\hline Age & $41(43 \%)$ & $29(30 \%)$ & $26(27 \%)$ & $96(100 \%)$ & 31.426 & 0.0001 \\
$41-50 y r s$ & $79(41 \%)$ & $64(33 \%)$ & $50(26 \%)$ & $193(100 \%)$ & $\mathrm{df}=2$ & \\
$51-60 \mathrm{yrs}$ & $36(25 \%)$ & $30(21 \%)$ & $75(54 \%)$ & $141(100 \%)$ & & \\
$>$ 60yrs & & & & & & \\
\hline Duration of & $44(41 \%)$ & $38(35 \%)$ & $26(24 \%)$ & $108(100 \%)$ & 29.394 & 0.0002 \\
menopause & $51(45 \%)$ & $37(33 \%)$ & $25(22 \%)$ & $113(100 \%)$ & $\mathrm{df}-2$ & \\
\hline 5 yrs & & & & & \\
\hline
\end{tabular}




\begin{tabular}{|l|c|c|c|c|c|c|}
\hline $\begin{array}{l}5-10 y r s \\
>10 y r s\end{array}$ & $61(29 \%)$ & $48(23 \%)$ & $100(48 \%)$ & $209(100 \%)$ & & \\
\hline $\begin{array}{l}\text { Family History of } \\
\text { hypertension }\end{array}$ & $20(12 \%)$ & $34(20 \%)$ & $115(68 \%)$ & $169(100 \%)$ & 13.88 & 0.00032 \\
Yes & $136(52 \%)$ & $89(34 \%)$ & $36(14 \%)$ & $261(100 \%)$ & $\mathrm{df}=1$ & \\
No & & & & \\
\hline
\end{tabular}

Current consumption of alcohol was found among 95(22.1\%), current tobacco users in the form of pan parag, gutka and zarda was observed among 109(25.3\%). Sedentary type of lifestyle was observed among 266(61.9\%), moderate among 160(37.2\%) and heavy workers among $4(0.9 \%)$. Using grading of obesity for Asians overweight were 130(30.2\%) and obese were 150(34.9\%). Extra salt intake was found among 156(36\%). Regular intake of fruits was found among 61(14\%); Regular intake of vegetables was found among 332(77\%); extra fat intake was noted among 20(4.7\%); Use of oral contraceptive was found none among them. Hypertension was found more among overweight and obese but not statistically significant. Statistically significant association was found with lifestyle and extra salt intake among modifiable risk factors. Table 2

Table 2: Modifiable risk factors associated with Pre Hypertension and Hypertension

\begin{tabular}{|c|c|c|c|c|c|c|}
\hline $\begin{array}{c}\text { Modifiable risk } \\
\text { factor }\end{array}$ & $\begin{array}{c}\text { Normal } \\
\mathrm{N}=156\end{array}$ & $\begin{array}{c}\text { Pre hypertension } \\
\mathrm{N}=123\end{array}$ & $\begin{array}{c}\text { Hypertension } \\
\text { N=151 }\end{array}$ & $\begin{array}{c}\text { Total } \\
\mathbf{N}=430\end{array}$ & $\begin{array}{c}\text { Chi } \\
\text { square df }\end{array}$ & $P$ value \\
\hline $\begin{array}{l}\text { Lifestyle } \\
\text { Sedentary } \\
\text { Moderate } \\
\text { Heavy }\end{array}$ & $\begin{array}{l}88(33 \%) \\
64(40 \%) \\
4(100 \%) \\
\end{array}$ & $\begin{array}{c}66(25 \%) \\
57(36 \%) \\
0(0 \%) \\
\end{array}$ & $\begin{array}{c}112(42 \%) \\
39(24 \%) \\
0(0 \%) \\
\end{array}$ & $\begin{array}{c}266(100 \%) \\
160(100 \%) \\
4(100 \%) \\
\end{array}$ & $\begin{array}{c}21.437 \\
\text { df- } 4\end{array}$ & 0.0002 \\
\hline $\begin{array}{l}\text { Extra salt intake } \\
\text { Yes } \\
\text { No }\end{array}$ & $\begin{array}{c}6(5 \%) \\
150(48 \%)\end{array}$ & $\begin{array}{l}30(26 \%) \\
93(30 \%)\end{array}$ & $\begin{array}{l}80(69 \%) \\
71(22 \%)\end{array}$ & $\begin{array}{l}116(100 \%) \\
314(100 \%)\end{array}$ & $\begin{array}{c}94 \\
\text { df- } 1\end{array}$ & 0.0001 \\
\hline $\begin{array}{l}\text { Body mass index } \\
\text { Underweight } \\
\text { Normal } \\
\text { Overweight + Obese }\end{array}$ & $\begin{array}{l}12(44 \%) \\
51(41 \%) \\
93(33 \%)\end{array}$ & $\begin{array}{l}10(37 \%) \\
30(24 \%) \\
83(29 \%)\end{array}$ & $\begin{array}{c}5(19 \%) \\
42(35 \%) \\
104(38 \%)\end{array}$ & $\begin{array}{l}27(100 \%) \\
123(100 \%) \\
280(100 \%)\end{array}$ & $\begin{array}{c}6.151 \\
\text { df-2 }\end{array}$ & 0.188 \\
\hline
\end{tabular}

\section{Discussion}

Our study found prevalence of pre hypertension among 29\% and hypertension among 35\% using JNC 7. Fareed et al among Ghanian postmenopausal women found very high prevalence of hypertension $83 \% .{ }^{11}$ Whereas Indian studies depicted in New Delhi urban slum by Nidhi Gupta et al was $39.6 \%$ as hypertension and $37 \%$ pre hypertension. This variation could be explained by ethnicity and different methods adopted. ${ }^{5}$

In our study significant association was found with increasing age. Song et al among Chinese women found high blood pressure with increasing age after adjusting for other confounding variables. ${ }^{12}$ Elisa et al in their study among Italian women found that with increase in parity the risk of hypertension increases but in our study this could not be elicited. ${ }^{13}$ This could be due to cultural factors and biological variables in different settings.

Our study found alcohol usage among 22\%, tobacco usage $25.3 \%$, extra salt intake $36 \%$ and nil usage of oral contraceptive usage. Statistical significant association was found with extra salt intake and sedentary lifestyle.

Bagdey et al found in their study among central Indian post menopausal women to have higher intake of salt $96 \%$, family history of hypertension $48 \%$, and low physical activity $47 \%$. They also found significant association with BMI. ${ }^{6}$ But similar to our study other factors such as alcohol use and oral contraceptive use to have negligible effect. Ruth et al among Hispanic postmenopausal women found significant association with body mass index and family history. ${ }^{14}$ Renu Tyagi et al also found obese and sedentary lifestyle to be more hypertensives among post menopausal women. ${ }^{7}$

Identification of pre hypertension and their modifiable risk factors among post menopausal women signals for early intervention in our study. One of the limitation of our study is that we could not assess stress among postmenopausal women.

\section{Conclusions}

Our study depicted prevalence of pre hypertension to be $29 \%$ and hypertension $35 \%$ among urban postmenopausal women which needs urgent requirement to be addressed. There was significant modifiable risk factors such as extra salt intake, body mass index and lifestyle. By adopting preventive strategies to curtail salt intake especially avoiding processed food, papads, chutneys and junk food, they can reduce salt intake. To maintain normal body weight and change their sedentary lifestyle to more active would help to reduce the risks of changing from pre 
hypertensive to hypertensive and also reduce their complications.

Acknowledgements: Our sincere thanks to all participants and health workers of urban slums who helped in the household survey. Special thanks to Dr. SP. Gomathi who has helped the training team to follow standard procedures to measure blood pressure.

\section{Source of Funding: Nil}

\section{Conflict of Interests: No}

\section{References}

1. Lim SS, Vos T, Flaxman AD, Danaei G, Shibuya K, Adair-Rohani $\mathrm{H}$, et al. A comparative risk assessment of burden of disease and injury attributable to 67 risk factors and risk factor clusters in 21 regions, 1990-2010: a systematic analysis for the Global Burden of Disease Study 2010. Lancet 2012;380:2224-2260. [PMC free article] [PubMed]

2. Fernández-Vega F, Abellán J, Vegazo O, De Vinuesa SG, Rodríguez JC, Maceira B, de Castro SS, Nicolás RR, Luño J. Angiotensin II type 1 receptor blockade to control BP in postmenopausal women: in uence of hormone replacement therapy. Kidney Int (Suppl) 2002 Dec;(82):S36-S41.

3. Atul Munshi. Indian menopause society programme, Member country session. Fourth scientific meeting of the Asia pacific menopause federation Monday 27 September 2010. Abstracts: 1 .

4. Hendrina A. DE BOO and Jane E. HARDING. The developmental origins of adult disease (Barker) hypothesis. Australian and New Zealand Journal of Obstetrics and Gynaecology 2006;46:4-14.

5. Gupta N, Vibha, Khandekar J, Jain A, Gupta S. Hypertension and its risk factors among postmenopausal women in Delhi. Ind J Comm Health. 2014;26(4):412416.
6. Prashant Shridhar Bagdey, Juveria Ahfaz Ansari, Rajan Kumar Barnwal. Prevalence and epidemiological factors associated with hypertension among post-menopausal women in an urban area of central India. Clinical Epidemiology and Global Health (2018), https://doi.org /10.1016/j.cegh.2018.02.008.

7. Renu Tyagi, Meenal Dhall, and Satwanti Kapoor. BioSocial Predictors of Hypertension among Premenopausal and Postmenopausal Women. SAGE Open JanuaryMarch 2015:1-12.

8. Appropriate body-mass index for Asian populations and its implications for policy and intervention strategies. WHO expert consultation. Lancet 2004;363:157-63.

9. Chobanian et al. The Seventh Report of the Joint National Committee on Prevention, Detection, Evaluation, and Treatment of High Blood Pressure: the JNC 7 report. JAMA 2003 May 21;289(19):2560-72.

10. Tulika Singh, Sanju Sharma Seetharamiah Nagesh. Socio-economic status scales updated for 2017. Int J Res Med Sci. 2017 Jul;5(7):3264-3267.

11. Fareed Kow Nanse Arthur, Michael Adu-Frimpong, James Osei-Yeboah, Faustina Obu Mensah and Lawrence Owusu The prevalence of metabolic syndrome and its predominant components among pre-and postmenopausal Ghanaian women. BMC Research Notes 2013, 6:446 http://www.biomedcentral.com/1756-0500/6/446.

12. Song, Lulu; Shen, Liju; Li, Hui* Age at natural menopause and hypertension among middle-aged and older Chinese women. Journal of hypertension 2018. 36(3);594-60. https://journals.lww.com/jhypertension/toc/2018/03000.

13. Elisa Giubertoni, Luca Bertelli, Ylenia Bartolacelli, Giorgia Origliani, Parity as predictor of early hypertension during menopausal transition, Journal of Hypertension 2013,31:501-507.

14. Ruth E. Zambrana, Lenny López, Gniesha Y. Dinwiddie, Roberta M. Ray. Prevalence and Incident Prehypertension and Hypertension in Postmenopausal Hispanic Women: Results from the Women's Health Initiative. American Journal of Hypertension 2014 march 27(3);372-381. 